\title{
Importância da Aplicação de Atividades Lúdicas no Ensino de Ciências para Crianças
}

\author{
Ana Carolina Rosa da Silva \\ Ludmylla Ribeiro dos Santos \\ Fabiana Mota da Silva \\ Elieide Livia Ribeiro da Costa \\ Paloma Lopes de Lacerda \\ Maria das Graças Cleophas
}

\begin{abstract}
Resumo
O presente trabalho relata a aplicação de uma oficina pedagógica, realizada na Unidade Escolar Rosa Teixeira de Castro, localizada na cidade de São Raimundo Nonato - PI. O público-alvo era composto de alunos do 30 ano do Ensino Fundamental I. O objetivo da oficina foi despertar o interesse dos alunos e professores para questões que rodeiam a temática ambiental. Com a execução da oficina, foi possível demonstrar como materiais simples, utilizados no dia a dia, podem, com criatividade, transformar-se em brinquedos e jogos, ganhando assim uma nova forma e uma nova simbologia. A produção e utilização das ferramentas pedagógicas, obtidas por meio da manipulação dos materiais recicláveis, estimularam a curiosidade dos alunos sobre os conteúdos didáticos utilizados na proposta lúdica, o que contribuiu com o fortalecimento das interações sociais dentro da sala de aula, além de terem sido observado indícios da apropriação sobre "um pensar e agir ecológico" pelos alunos.
\end{abstract}

Palavras-chave: Oficina Pedagógica, Ludicidade, Educação Ambiental.

\begin{abstract}
This paper describes the implementation of an educational workshop, held at the School Unit Rosa Teixeira de Castro, located in São Raimundo Nonato - PI. The audience was composed of students of the $3^{\text {rd }}$ year of elementary school. The purpose of the workshop was to awaken the interest of students and teachers to issues surrounding environmental issues. With the implementation of the workshop was possible to show how simple materials, used in everyday life, can, creatively, turn into toys and games, thus gaining a new form and a new symbology. The production and use of educational tools, obtained through the manipulation of recyclable materials, stimulated students' curiosity about the educational content used in playful proposal and contributed to the strengthening of social interactions within the classroom, as well as evidence of having been observed ownership on a "think and act green" by students.
\end{abstract}

Keywords: Pedagogical Workshop, playfulness, Environmental Education. 


\section{Introdução}

As ferramentas didático-pedagógicas vêm ganhando cada vez mais espaço no universo escolar, visto que estimulam o cognitivo dos alunos durante o processo de ensino e aprendizagem. Sendo assim, a elaboração de brinquedos com fins pedagógicos, produzidos por meio do uso de materiais reciclados, vem-se tornando uma ótima opção para favorecer a atividade em grupo, estimular a criatividade e ainda promover ensinamentos importantes para a construção ou fortalecimento de valores sobre a consciência ecológica.

Para Freire (1993), qualquer material será mais eficaz se for variado. Decerto, isto corrobora a hipótese de que, para a construção do conhecimento em sala de aula, é importante a utilização de inúmeras alternativas metodológicas, e que estas possam ser complementadas com o uso de estratégias didáticas, tais como jogos, brinquedos pedagógicos, etc. Neste sentido, construir e inserir no cotidiano escolar ferramentas didático-pedagógicas que incentivem o aluno a desenvolver ou estimular a construção de conhecimentos é, sobretudo, possibilitar aos discentes uma aprendizagem mais inovadora e cativante, pois a mesma pode tornar os conteúdos curriculares prazerosos em relação a sua assimilação, fomentado, assim, habilidades cognitivas para a edificação de aprendizagens.

Ultimamente, é cada vez mais crescente o número de pesquisadores da área de educação em Ciências que procuram compreender a relação entre o lúdico e os processos de ensino e aprendizagem, com vistas à promoção de habilidades e competências, a citar, Souto-Manning (2011); Cunha (2012); Hainey et al. (2013); Gouvêa e Suart (2014); Brão e Pereira (2015), entre tantos outros. Neste sentido, a utilização de atividades lúdicas pode ser considerada potencialmente promissora para subsidiar a melhoria da qualidade escolar, pois pode contribuir para favorecer o aprendizado sobre conteúdos didáticos. Contudo, vale salientar que a elaboração e utilização de ferramentas pedagógicas que tragam bons resultados cognitivos e que ofereçam uma bagagem conceitual consistente para uma boa formação de indivíduos que estejam aptos a aprender de forma diferenciada e dinâmica não é uma tarefa fácil para muitos educadores, pois requer amplo planejamento e dedicação para que a atividade lúdica se torne eficaz, a fim de mobilizar habilidades mentais para a construção de conhecimentos.

No que tange à preservação e conservação do meio ambiente, a humanidade vem enfrentando sérios problemas ao longo dos séculos. É notório que as novas tecnologias são, sobretudo, preferenciais para a maioria das crianças, e o que se observa é que, em pouco tempo, videogames, tablets, celulares e jogos eletrônicos passaram a ocupar o lugar dos brinquedos tradicionais. Atrelada a tal situação, ainda há um avanço na produção tecnológica que provocou um aumento significativo no padrão de consumo desses acessórios.

As facilidades oferecidas ao consumidor têm estimulado a população, desde as menores faixas etárias, a consumir exageradamente, mesmo sem haver necessidade, gerando, assim, 
toneladas de lixo. Tal consumismo é visto como uma das principais causas da degradação do meio ambiente. Desse modo, o lixo tem apresentado seu lado calamitoso,

\begin{abstract}
"pois é um indicador curioso de desenvolvimento de uma nação. Quanto mais pujante for a economia, mais sujeira o país irá produzir. É o sinal de que o país está crescendo, de que as pessoas estão consumindo mais. O problema está ganhando uma dimensão perigosa por causa da mudança no perfil do lixo. Na metade do século $X I X$, a composição do lixo era predominantemente de matéria orgânica, de restos de comida. Com o avanço da tecnologia, materiais como plásticos, isopores, pilhas, baterias de celular e lâmpadas são presença cada vez mais constante na coleta" (NOGUERA, 2010, p. 5).
\end{abstract}

Logo, percebe-se que a luta pela preservação e conservação do meio ambiente deve ser travada por todos. Com este pensamento, os PCNs inserem no currículo escolar essa questão, explicitando a obrigatoriedade do ensino de Educação Ambiental no cotidiano de alunos do ensino fundamental e médio das escolas públicas ou privadas. Neste contexto, Carvalho (2008) afirma que:
"A Educação Ambiental surge a partir das preocupações da sociedade com o futuro e com a qualidade de vida das presentes e futuras gerações, sendo considerada uma alternativa que visa construir novas maneiras das pessoas se relacionarem com o meio ambiente" (CARVALHO, 2008, p. 51).

Portanto, ressalte-se a eminente importância de educar os futuros cidadãos brasileiros para a formação de indivíduos mais críticos e conscientes sobre as consequências que seus atos presentes podem trazer às futuras gerações. Corroborando ainda com Carvalho (2008), entram em cena Fernandes et al. (2003, p. 01), esclarecendo que "a percepção ambiental pode ser definida como sendo uma tomada de consciência pelo homem, ou seja, o ato de perceber o ambiente que se está inserido, aprendendo a proteger e a cuidar do mesmo".

Pressupondo essa necessidade na formação de sujeitos críticos e atuantes quanto aos problemas ambientais enfrentados pela humanidade, tem-se a inserção da Educação Ambiental nos currículos escolares. Tal obrigatoriedade traz uma discussão pertinente, que gira em torno de como trabalhar o tema Educação Ambiental com crianças e adolescentes que já nascem em uma sociedade que aprecia o consumismo como forma de diversão. No entanto, tudo leva a crer que a Educação Ambiental deva ser intrínseca do próprio papel da sociedade, não se restringindo apenas ao contexto escolar, isto porque a "escola é o lugar social da educação; no entanto, a educação escolar não é a única fonte de aprendizado do ser humano" (SULAIMAN, 2011, p. 647).

Ainda sobre este aspecto, Nóbrega et al. (2011) afirmam que é necessário conferir à Educação uma característica pragmática, mas não utilitarista, com caráter de agente 
transformador quanto às práticas e à atuação na realidade local. Corroborando essa argumentação, a Educação Ambiental é fundamental para a formação dos nossos alunos, pois a mesma deve favorecer a adoção de atitudes adequadas para a preservação do meio ambiente, e, respectivamente, para a própria humanidade. Para isso, é necessário que educadores trabalhem nas escolas, aspectos que estimulem o favorecimento de atitudes e valores com o intuito de fomentar a consciência ambiental, gerando, assim, cidadãos críticos e responsáveis com o meio ambiente.

De acordo com esse pensamento, os Parâmetros Curriculares Nacionais (1997) requerem a obrigatoriedade da Educação Ambiental em sala de aula, porém não oferecem meios ou estratégias metodológicas que sirvam de aporte para o professor, ou seja, não dão condições suficientes para que ele possa desenvolver temáticas em sala de aula que envolvam a Educação Ambiental. Diante deste contexto, pode-se refletir que, provavelmente, esta problemática é oriunda de lacunas causadas durante a formação inicial dos professores, o que gera obstáculos perante o processo de ensino. Como resultado disto, geralmente há um ensino de Educação Ambiental defasado, fragmentado e desconectado das demais disciplinas, quando este deveria ser uma extensão das demais, promovendo, assim, uma complementaridade crítica-reflexiva sobre o aprendizado dos alunos.

Diante disso, observa-se que a interdisciplinaridade deveria permear todo o contexto escolar, principalmente no que tange à educação ambiental. Reigota (2001) defende a Educação Ambiental numa perspectiva educativa, pois

\section{"(...) a Educação Ambiental, como perspectiva educativa, pode estar presente em todas as disciplinas, quando analisa temas que permitem enfocar as relações entre a humanidade e o meio natural, e as relações sociais, sem deixar de lado as suas especificidades" (REIGOTA, 2001, p. 25).}

A literatura relata vários autores que tratam deste aspecto, entre eles Tristão (2004), que defende a abordagem interdisciplinar na educação ambiental. Como também Delizoicov e Zanetic (1993), que ressaltam a implementação de uma postura interdisciplinar, perante o currículo escolar, que objetive superar o procedimento dominante na forma de se escolher os conteúdos escolares, no qual estes, são frequentemente desvinculados dos aspectos históricos que os originaram e estão afastados das questões presentes no cotidiano. Mas o que se observa na prática, ainda, é que a Educação Ambiental nas escolas é dada de forma dissociável, acarretando conjunturas indesejáveis, em que os professores não conseguem aplicá-la numa perspectiva voltada para confluências de conhecimentos disciplinares.

Nas últimas décadas, os professores vêm sendo alertados para necessidade constante de atualização sobre a sua prática profissional (SOUZA e GOUVÊA, 2006). Isto posto, Castoldi e Polinarski (2009) alegam que grande parte dos professores tende a adotar métodos mais 
tradicionais de ensino, pelo receio do novo ou por estar acostumados com o velho sistema educacional. Neste viés, percebe-se um discurso cômodo por parte dos professores, o qual vai de encontro à necessidade de estabelecer espaços que permitam ao estudante ter acesso a um processo de ensino e aprendizagem mais significativo para ele, ou seja, que promova "estimulação, a variedade, o interesse, a concentração e a motivação ..." (MOYLES, 2002, p. 21) sobre seu próprio aprendizado.

Assim, visando colaborar com o processo de ensino, esta proposta de trabalho se fundamenta na utilização da Pedagogia dos 3R's (reutilização, reaproveitamento e reciclagem), tendo como aporte a temática ambiental, e sendo esta subsidiada pela aplicação de uma oficina pedagógica, visto que Vieira e Valquind (2002) entendem que:

"Na oficina surge um novo tipo de comunicação entre professores e alunos. $\dot{E}$ formada uma equipe de trabalho, onde cada um contribui com sua experiência. $O$ professor é dirigente, mas também aprendiz. Cabe a ele diagnosticar o que cada participante sabe e promover o ir além do imediato" (VIEIRA e VALQUIND, 2002, p. 17).

A oficina pedagógica promovida visou à confecção de brinquedos e jogos com fins didáticos, tendo como matérias-primas materiais recicláveis. A mesma foi aplicada em uma escola pública, localizada na cidade de São Raimundo Nonato, sudeste do estado do Piauí. Vale destacar que neste cenário a coleta de lixo ainda é precária e não há um descarte correto, e tampouco políticas públicas que contribuam com melhorias nas condutas dos moradores em relação a este problema, pois o mesmo é despejado em um "lixão" a céu aberto, e não existem ONGs nem cooperativas para reciclagem. Também não há saneamento básico. No tocante às condições físicas das escolas, muitas são precárias, não informatizadas, e sem espaços destinados a laboratórios para aulas experimentais de Ciências.

Diante de tais aspectos, o objetivo da nossa proposta consistiu em incentivar e auxiliar professores e alunos na construção de ferramentas pedagógicas, lúdicas, como brinquedos e jogos, a partir de materiais que seriam descartados, promovendo, assim, uma discussão sobre a prática da educação ambiental, além de favorecer a produção de "novos materiais" que possam ser utilizados nas aulas de Ciências por estes professores, posteriormente.

\subsection{A importância dos brinquedos e jogos pedagógicos para apropriação do lúdico}

Sabe-se que a prática docente é recheada de desafios. Dentro desse processo, há, cada vez mais, alunos "antenados" e "vidrados" por tecnologias, e professores que precisam urgentemente alterar sua práxis docente, em prol do acompanhamento das constantes mudanças que ocorrem 
no ensino. Assim, inúmeras estratégias vêm sendo utilizadas pelos educadores, em virtude destas transformações. Sobre esse papel do professor, Moyles (2002) nos diz que:

"Devemos oferecer uma variedade de situações e inovações dentro da sala de aula, que permitam diferentes oportunidades para diferentes crianças e, mais importantes, temos de assegurar que cada criança tenha oportunidade de explorar adequadamente um novo meio ou situação - e isso significa tentar explorar as experiências com palavras, assim como por meio do brincar" (MOYLES, 2002, p. 57).

O uso do ludismo no meio escolar já se configura como uma prática promissora e eficiente para a aprendizagem, principalmente no ensino das Ciências, o qual precisa de estratégias didáticas que permitam amenizar a abstração, pelos alunos, do entendimento conceitual. Seguindo esta vertente, os brinquedos e jogos didáticos são indicados para utilização nas aulas, por favorecerem aos alunos um ambiente rico que enaltece a interação social, o raciocínio lógico e a tomada de decisão. De acordo com as concepções de Vygotsky (1962 apud SILVA e HJORTH, 2009), em sua teoria sobre o desenvolvimento cognitivo, a criança aprende por meio de ferramentas que servem para pensar, pois estas contribuem para a resolução de problemas, favorecem compartilhamento de experiências, e promovem a interação. Ou seja, para Vygotsky (2007), é nas interações com as atividades operacionais que envolvem simbologia e brinquedos que o educando aprende a agir numa esfera cognitiva, pois se incentiva o trabalho em equipe e a interação aluno-professor; auxilia-se no desenvolvimento do raciocínio e habilidades; e se facilita o aprendizado de conceitos (VYGOTSKY, 1989).

Para Antunes (1999, p. 38), “[...] os jogos ou brinquedos didáticos são desenvolvidos com a intenção explícita de provocar uma aprendizagem significativa, estimular a construção de um novo conhecimento e, principalmente, despertar o desenvolvimento de uma habilidade operatória". O uso destes, com fins pedagógicos, aponta para a relevância desse instrumento perante situações de ensino e aprendizagem, além do desenvolvimento infantil, conforme nos diz Kishimoto (1999). Cavalcanti (2011, p. 27) revela que "por meio do jogo, o professor utiliza-se de um artifício lúdico, e tem a possibilidade de uma real interação com seus alunos, o que permite conduzi-los a uma autonomia intelectual e moral". Assim, os brinquedos didáticos também abarcam esta dimensão. É por meio deles, e das brincadeiras que se desencadeiam espontaneamente, que a criança tem a oportunidade de desenvolver um canal de comunicação, uma abertura para o diálogo com o mundo dos adultos, onde "ela restabelece seu controle interior, sua autoestima e desenvolve relações de confiança consigo mesma e com os outros" (GABARINO et al., 1992 apud BOMTEMPO, 2009, p. 69).

Contudo, elaborar jogos e/ou brinquedos pedagógicos requer dos professores amplo planejamento e metas bastante definidas, objetivando, de tal modo, atingir os objetivos metodológicos almejados. Para Felício (2011), é importante uma "intencionalidade lúdica", ou

DOI: Em andamento. 
seja, ela seria uma atitude intencional, voltada e orientada ao equilíbrio do aspecto prazeroso e pedagógico da atividade a ser desenvolvida pelo professor. Sem embargo, pode-se entender que a "intencionalidade lúdica" é intrínseca a cada profissional docente. Cabe aos cursos de Licenciatura promover uma formação inicial pautada em estratégias inovadoras, favorecendo, assim, a formação de profissionais comprometidos com a inserção de atividades diferenciadas em suas aulas.

Nessa esteira de ideias, acredita-se que, para uma ressignificação no ensino das Ciências, seja necessário haver, por parte dos professores, uma renovação na teoria da Ciência, acompanhada por uma repaginação didático-metodológica de suas aulas (CACHAPUZ et al., 2011). Nesse sentido, o uso dos jogos no contexto escolar pode contribuir com tal mudança, pois ele promove um exercício de diálogo, decisão em grupo e consenso (COLLINS et al., 2005); já para Soares (2013), ao se propor um jogo e/ou atividades lúdicas, faz-se a união entre divertimento e aprendizagem, quebrando-se, assim, a formalidade entre alunos e professores, além de socializálos e fazê-los construir conjuntamente o ensino.

\section{Delineamento metodológico}

Esta pesquisa teve como foco 29 alunos do 3o ano do ensino fundamental I, da Unidade Escolar Rosa Teixeira, localizada no município de São Raimundo Nonato - PI. Os aspectos metodológicos deste trabalho foram subdivididos em três (03) etapas distintas. Sendo elas:

\section{0 etapa: Elaboração e confecção de alguns brinquedos pedagógicos}

Nesta etapa foram elaborados e confeccionados brinquedos e jogos com materiais recicláveis, visando produzir ferramentas didáticas que pudessem contribuir com desenvolvimento o fortalecimento da aprendizagem dos alunos sobre alguns conteúdos de Ciências, vistos no 3o ano do Ensino Fundamental I (Quadro 1), além de inserir alguns temas sobre Educação Ambiental. A ludicidade foi o fio condutor e promotor desta proposta, que teve como meta principal a aprendizagem e a ressignificação de valores ecológicos nos alunos. Os brinquedos e jogos confeccionados estão descritos de acordo com a Quadro 1. 
Quadro 1 - Brinquedos e/ou jogos produzidos versus materiais utilizados para sua confecção.

\begin{tabular}{|c|c|}
\hline $\begin{array}{l}\text { ATIVIDADES LÚDICAS (BRINQUEDOS E } \\
\text { JOGOS) }\end{array}$ & MATERIAIS UTILIZADOS \\
\hline $\begin{array}{l}\text { Jogo Caixinha da memória - este } \\
\text { brinquedo continha imagens de animais já } \\
\text { extintos e de outros que estão ameaçados de } \\
\text { extinção; durante e depois da produção da } \\
\text { caixinha, seguiu-se explicando o porquê de } \\
\text { aqueles animais não existirem mais e de outros } \\
\text { que corriam risco de ser extintos, relacionando } \\
\text { com as questões ambientais e a participação do } \\
\text { homem neste contexto. }\end{array}$ & $\begin{array}{l}\text { Para este brinquedo, foram utilizados } \\
\text { tintas; caixas de fósforos; mini-imagens de } \\
\text { animais extintos e papel para decorar. }\end{array}$ \\
\hline $\begin{array}{l}\text { Jogo da velha - Este brinquedo } \\
\text { continha caráter de raciocínio lógico, instigando } \\
\text { o pensamento dos alunos sobre o conteúdo de } \\
\text { alimentos de origem animal e vegetal. }\end{array}$ & $\begin{array}{l}\text { Caixas de ovos; tampinhas de garrafa } \\
\text { pet e tintas para colorir. }\end{array}$ \\
\hline $\begin{array}{l}\text { Bolinhas de gude na garrafa pet - Este } \\
\text { brinquedo de estratégia visava explicar para as } \\
\text { crianças, por meio do raciocínio lógico, } \\
\text { conceitos relacionados à densidade dos } \\
\text { materiais. }\end{array}$ & $\begin{array}{l}\text { Palitos para churrasco; cola; bolinha de } \\
\text { gude; bolas de isopor e canudos. }\end{array}$ \\
\hline $\begin{array}{l}\text { Cantinho da Leitura - Este brinquedo } \\
\text { proporcionou a criação de um ambiente lúdico } \\
\text { para incentivar a leitura pelas crianças; ao } \\
\text { entrar no cantinho da leitura, elas podiam } \\
\text { escolher diferentes historinhas sobre o meio } \\
\text { ambiente. }\end{array}$ & $\begin{array}{l}\text { Caixa de papelão; fitas; cola; papel } \\
\text { sulfite. }\end{array}$ \\
\hline
\end{tabular}

\section{2o etapa: Ação na escola: a oficina}

A execução da oficina foi conduzida por um grupo de professores em formação inicial em Ciências da Natureza, discentes da Universidade Federal do Vale do São Francisco (UNIVASF). Foram explicados, para os alunos da turma, alguns conceitos sobre reciclagem, reutilização e redução do consumo dos materiais, etc., além de se ressaltar a importância do papel da consciência ambiental, não apenas nas escolas, mas, principalmente, fora dela. Também foram

DOI: Em andamento. 
discutidos assuntos referentes à problemática do lixo produzido pela sociedade e formas de descartá-lo corretamente, entre outros. Após esta etapa, foi explanado, passo a passo, como os "brinquedos e jogos" poderiam ser confeccionados a partir de materiais simples, sendo que estes já haviam sido previamente utilizados e seriam descartados no lixo. Paralelamente a isso, foram esclarecidas, também, algumas formas de reduzir o consumo de diversos materiais, ou como estes poderiam ser reutilizados de forma prática.

\section{3 etapa: A análise}

Ao término da oficina, foi realizada uma breve discussão sobre os benefícios que ações deste tipo trazem ao meio ambiente e à sociedade em sua totalidade. Para avaliação das atividades lúdicas, foi empregada uma metodologia que analisasse todas as percepções dos alunos, a fim de compreendê-las fenomenologicamente. Tal metodologia está em conformidade com o pensamento de Martins e Bicudo (1989), pois os mesmos defendem a análise qualitativa, buscando não os fatos em si, mas os significados desses fatos para os sujeitos. De acordo com Bicudo (2000), um meio para analisar e interpretar fenomenologicamente os dados é transformálos em termos textuais, visando a sua essência e sua transcendência.

Segundo Rojas et al. (2012), a investigação fenomenológica abarca três momentos distintos, ou seja: um olhar atento para o fenômeno observado; a descrição sobre o fenômeno e a não influência das crenças preestabelecidas que medeiam a realidade do fenômeno. Assim, na fenomenologia, as significações são válidas quando os dados, plenos e intuitivos, correspondem exatamente ao ato, expressivo (e vazio), que determina a sua significação (POUPART et al., 2012).

\section{Refletindo sobre a aplicação da oficina}

A aplicação das atividades lúdicas, no formato de oficina, aconteceu após o planejamento das ações propostas por um grupo de alunos, em formação inicial em Ciências da Natureza, como mencionado anteriormente. A aplicação da oficina na escola foi amplamente acolhida pelos alunos e professores, e a participação destes, frente à produção e utilização dos brinquedos e jogos, foi bastante expressiva. A oficina teve duração de 4 horas. Os alunos foram divididos em equipes, contendo quatro ou cinco componentes.

Todas as regras referentes às atividades foram definidas e repassadas às equipes, entretanto, observou-se que apenas alguns alunos estavam atentos às informações; outros, em menor quantidade, não demonstraram interesse sobre a ação que estava sendo executada. Contudo, foi respeitada a voluntariedade e a não obrigatoriedade, aspecto defendido por Huizinga (1980). Vale destacar que, após certo tempo, esta minoria de alunos, antes indiferente à atividade, imergiu-se na mesma de forma natural, fortalecendo o espírito de colaboração em sua respectiva equipe. Certamente, estes alunos se sentiram atraídos pela parte lúdica que a oficina demonstrava, pois, certamente, por meio das brincadeiras e jogos realizados, foram encorajados

92 DOI: Em andamento. R. Bras. de Ensino de C\&T 
a participar, talvez pelo ímpeto de curiosidade sobre toda a movimentação que a oficina causou. Pode-se afirmar que, certamente, a semelhança com algumas experiências vivenciadas no campo das atividades cotidianas fez com que estes alunos despertassem a curiosidade em participar das ações propostas pela oficina, pois ela promoveu motivação, levando os alunos, de modo intencional, a apreender certos conteúdos. Assim, a brincadeira permite à criança vivenciar o lúdico e descobrir-se a si mesma, apreendendo a realidade e tornando-se capaz de ampliar seu potencial criativo (SIAULYS, 2005).

Observou-se, também, um grande interesse por parte dos alunos em ajudar a confeccionar os brinquedos e jogos, visto que a oficina despertou o interesse deles, gerando liberdade em colocar em prática a sua criatividade e intelectualidade, e, decerto, esta liberdade intelectual forneceu indícios de que a mesma favoreceu o aprendizado destes alunos perante a aquisição de conhecimentos científicos atrelados à atividade proposta. Houve inúmeros questionamentos acerca da necessidade de se estar produzindo aqueles materiais, e por que estavam sendo inseridos os "conteúdos da tia". Neste caso, eles perceberam a intencionalidade da oficina, pois conseguiram notar que as atividades lúdicas propostas continham conteúdos que foram ministrados em sala de aula pela professora da turma. No condizente à atitude da professora, esta acompanhou boa parte da aplicação da proposta, fazendo algumas intervenções para corrigir eventuais erros apresentados pelos alunos. No entanto, ela não acompanhou toda a oficina, ausentando-se da sala após certo tempo, provavelmente isso ocorreu quando ela percebeu que todos os alunos estavam concentrados e dedicando-se integralmente à execução das tarefas propostas pela oficina.

Um dos brinquedos produzidos, o "Cantinho da Leitura" (Figura 1), despertou o interesse dos alunos em entrar na casinha (cantinho) e investigar os recortes de revistas ou folhetos, contendo temas sobre o meio ambiente, tais como: poluição da água; preservação ambiental; lixo, etc. Na Figura 1, o que nos chamou a atenção foi o fato de que, enquanto um aluno utiliza o cantinho da leitura, outro espera ansiosamente o seu momento para utilizá-lo. 


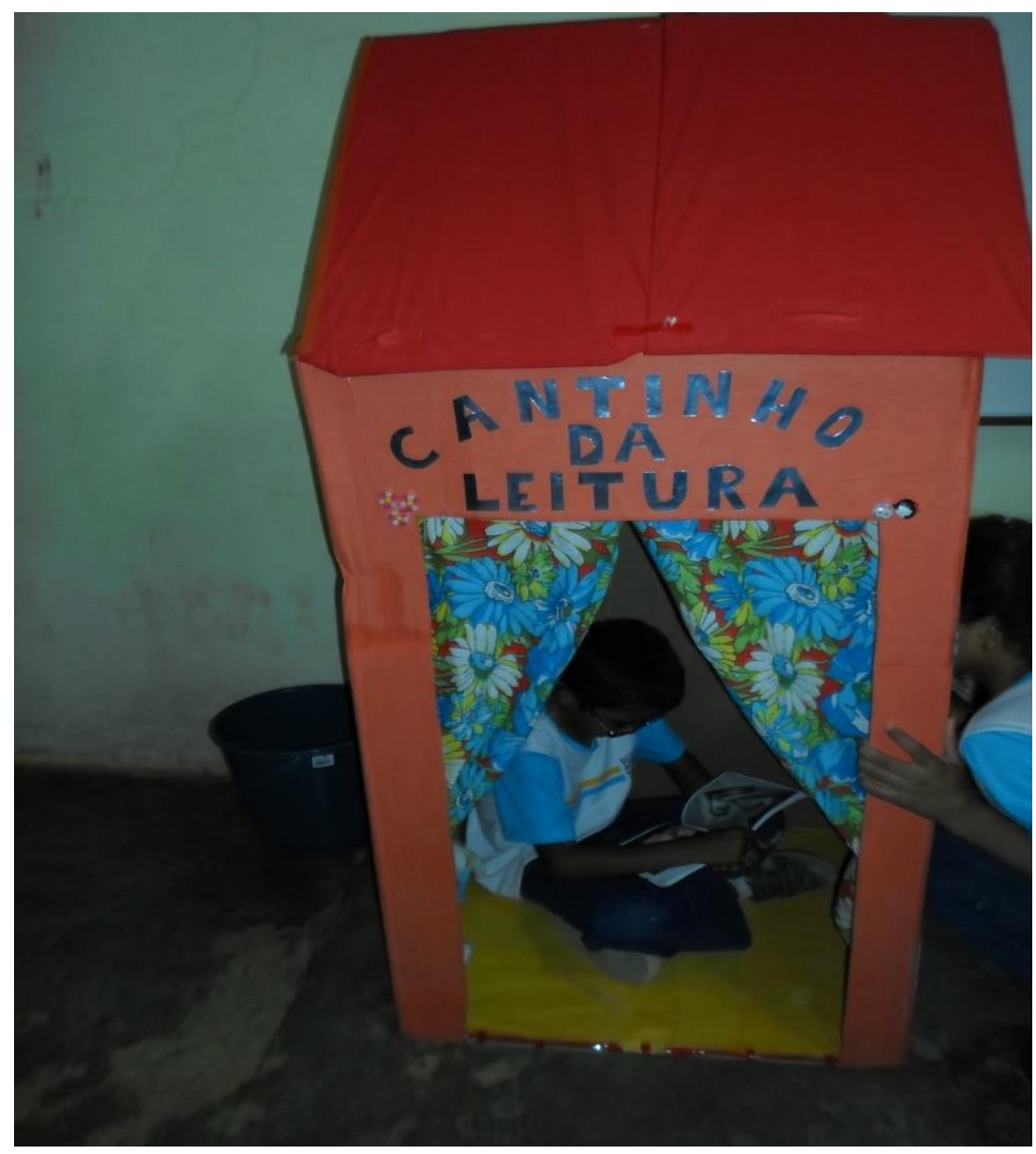

Figura 1 - Aluno realizando leitura dentro do "Cantinho da Leitura".

Notou-se que, para este grupo de alunos, não é comum em seu cotidiano escolar a inserção deste tipo de atividade lúdica. Aos poucos, os alunos foram perdendo toda a timidez inicial e, cada vez mais, se envolveram com a temática. De tal modo, percebeu-se que toda a oficina favoreceu a assimilação e/ou revisão dos conteúdos didáticos inseridos na proposta. Isso vai ao encontro do que pensa Packer (1994, p. 273), ao afirmar que brincar é uma atividade prática "na qual a criança constrói e transforma seu mundo, conjuntamente, renegociando e redefinindo a realidade". Desta forma, ao brincar, os alunos estavam cognitivamente absorvendo valores importantes sobre a Educação Ambiental e fortalecendo o aprendizado sobre os conteúdos já vistos em sala de aula anteriormente. Ao observar as falas de algumas crianças, nota-se a percepção subjetiva de modo positivo, fornecendo, assim, indícios que corroboram possíveis mudanças de concepções em relação a sua postura frente à reutilização do lixo e à preservação ambiental. As opiniões dos alunos sobre a aplicação da oficina são apresentadas abaixo, por meio de fragmentos textuais, presentes no Quadro 2. 
Quadro 2 - Descrição das falas de alguns alunos ao serem questionados sobre os itens abaixo:

\begin{tabular}{|c|c|}
\hline $\begin{array}{l}\text { QUAL A IMPORTÂNCIA DA } \\
\text { REUTILIZAÇÃO DO LIXO? }\end{array}$ & $\begin{array}{c}\text { QUAL SUA OPINIÃO SOBRE A } \\
\text { IMPORTÂNCIA DA UTILIZAÇÃO DESTES } \\
\text { MATERIAIS (ATIVIDADES LÚDICAS) NO DIA A } \\
\text { DIA DA ESCOLA? DESCREVA O QUE VOCÊ } \\
\text { ACHOU DA APLICAÇÃO DA OFICINA. }\end{array}$ \\
\hline $\begin{array}{l}\text { Aluno 1: "Porque diminui o lixo na } \\
\text { cidade". }\end{array}$ & $\begin{array}{l}\text { Aluno 6: "Eu achei muito bom a sua aula } \\
\text { de leitura". (referindo-se à casinha da leitura) }\end{array}$ \\
\hline $\begin{array}{l}\text { Aluno 2: "Muito bom reciclar para as } \\
\text { pessoas não pegarem doenças". }\end{array}$ & Aluno 1: "Gostei". \\
\hline $\begin{array}{l}\text { Aluno 3: "Pegar para fazer brinquedos } \\
\text { para as crianças brincarem". }\end{array}$ & Aluno 7: "Interessante". \\
\hline $\begin{array}{l}\text { Aluno 4: "A importância do lixo que a } \\
\text { gente pode reaproveitar e pegar para reciclar } \\
\text { e fazer brinquedos". }\end{array}$ & $\begin{array}{l}\text { Aluno 8: "Eu gostaria muito que viessem } \\
\text { mais vezes". }\end{array}$ \\
\hline $\begin{array}{l}\text { Aluno 5: "Por causa de não causa mal } \\
\text { ao meio ambiente e também junte o lixo para } \\
\text { reciclar e formar novas coisas". }\end{array}$ & $\begin{array}{l}\text { Aluno 4: "Eu achei muito legal e muito } \\
\text { divertido e também eu achei muito legal fazer os } \\
\text { brinquedos". }\end{array}$ \\
\hline
\end{tabular}

De acordo com Kishimoto (2003), o jogo e/ou atividades lúdicas são promotores de aprendizagens e desenvolvimento, além de serem considerados, nas práticas escolares, como verdadeiros aliados importantes para o ensino, visto que proporcionam aos discentes inúmeras situações lúdicas. Já Ronca (1989, p. 27) acredita que "o movimento lúdico, simultaneamente, torna-se fonte prazerosa de conhecimento, pois nele a criança constrói classificações, elabora sequências lógicas, desenvolve o psicomotor e a afetividade e amplia conceitos das várias áreas da ciência".

É importante destacar que, atualmente, muitos alunos criticam as aulas de Ciências por apresentarem um ar monótono, e uma exacerbada falta de elo entre a teoria e a prática, além de uma elevada abstração, etc. Por outro lado, ao utilizar atividades lúdicas, tornam-se perceptíveis os inúmeros benefícios que estas podem agregar aos processos de ensino e aprendizagem, sendo um legítimo meio de observações das manifestações de diferentes habilidades cognitivas exibidas pelos alunos. Isto nos faz compreender a importância de se refletir sobre a prática docente em

DOI: Em andamento. 
relação à inserção de alternativas metodológicas que sejam bem planejadas, e que possam, sobretudo, oferecer ao aluno um ensino que prime pela aquisição de conhecimento, no qual o professor, diante deste processo, possa atuar como mediador, auxiliando o aluno a usar corretamente suas habilidades cognitivas, amenizando, assim, a dicotomia existente entre os conteúdos didáticos impostos pelo currículo e o cotidiano dos alunos.

Segundo Fialho (2007), é válido ressaltar que os alunos necessitam muito mais do que simplesmente ouvir, escrever e resolver exercícios que atendam ao currículo proposto no início do ano. Cabe ao professor proporcionar espaços para a construção de aprendizagens para os alunos, promovendo, assim, a consolidação de conhecimentos que sejam pautados na constituição de saberes, originados por diferentes métodos, ou seja, um processo não unívoco em termos de metodologias, mas, sim, ancorados em diversas estratégias e ferramentas de ensino.

Assim sendo, inserir ferramentas pedagógicas no ambiente escolar, produzidas a partir de materiais reciclados, contribui eficazmente para o processo de ensino e aprendizagem, pois favorece o desenvolvimento de habilidades cognitivas distintas, além de fomentar atitudes corretas em relação ao meio ambiente. Para Rizzi et al. (1987), o uso dos jogos e/ou brincadeiras atrai o aluno de forma descontraída, pois, por intermédio deles, é capaz de fazer uso de esquemas mentais aplicados à realidade que o cerca, modificando o real de acordo com suas necessidades. As crianças, quando transitam por uma situação lúdica, passam a apreender o conhecimento proposto de forma descontraída (KOLB e KOLB, 2010).

De acordo com o observado, os alunos participaram efetivamente da oficina (Figura 2). Fizeram inúmeros questionamentos e debateram sobre as questões ambientais inseridas perante os jogos e brinquedos desenvolvidos, enquanto estes eram produzidos por eles mesmos. 


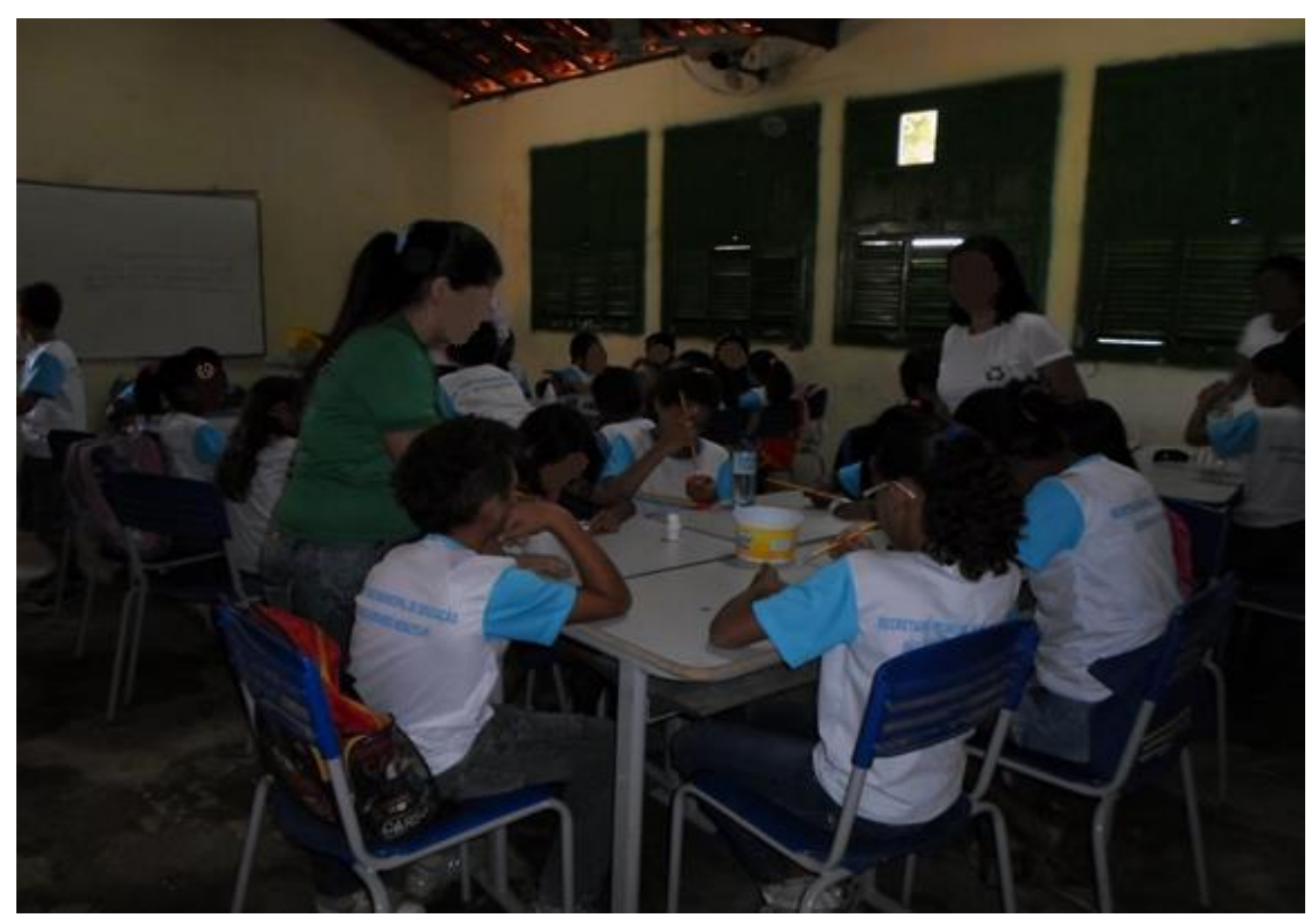

Figura 2 - Alunos do 3o ano do Ensino Fundamental l participando ativamente da oficina.

Para Bruner e Ratner (1978), a criança, ao brincar, tem a possibilidade de ludicamente solucionar os problemas que Ihe são apresentados. Ou seja, ela possui uma motivação adicional e involuntária (proporcionada pelo ludismo), que the favorece de forma espontânea a capacidade de raciocinar, deduzir, interpretar, entre tantas outras. Desta forma, foi percebido que a oficina proposta atingiu seu objetivo principal, ou seja, ofertar a possibilidade de discutir e atrelar a Educação Ambiental a um contexto lúdico, com vistas à solução de problemas. As crianças demonstraram interesse nas questões propostas, e apresentaram, dentro de sua linguagem própria, responsabilidade diante dos assuntos relacionados ao meio ambiente. Outro ponto evidenciado está centrado no processo colaborativo evidenciado entre as crianças, pois elas discutiram e se ajudaram de forma recíproca. Acerca deste aspecto colaboracionista, ele foi fundamental durante a oficina, pois os estudantes trabalharam em conjunto para tomar decisões e resolver os problemas didáticos que estavam inseridos na atividade lúdica. Quando questionadas sobre a aplicação da oficina, as respostas foram distintas, o que denota que a percepção subjetiva dos estudantes sobre a oficina foi positiva. Isso pode ser visto por meio da observação do discurso de alguns alunos após o término da oficina, exibido no Quadro 3. 
Quadro 3 - Descrição das falas de alguns alunos após a

aplicação da oficina.

\begin{tabular}{|c|c|}
\hline \multicolumn{2}{|c|}{ RECICLÁVEIS? } \\
\hline $\begin{array}{l}\text { Aluno 1: "Gostei mais do jogo da } \\
\text { velha". }\end{array}$ & $\begin{array}{l}\text { Aluno 6: "Achei engraçada a } \\
\text { casinha da leitura. É preciso salvar os } \\
\text { animais". }\end{array}$ \\
\hline $\begin{array}{l}\text { Aluno 2: "Foi muito interessante } \\
\text { economizar". }\end{array}$ & $\begin{array}{l}\text { Aluno 7: "O jogo da memória é } \\
\text { difícil". }\end{array}$ \\
\hline Aluno 3: "Interessante". & $\begin{array}{l}\text { Aluno 8: "Achei muito bom, muito } \\
\text { divertido fazer brinquedos a partir do lixo". }\end{array}$ \\
\hline Aluno 4: "Ótimo". & $\begin{array}{l}\text { Aluno 9: "Eu gostei mais dos } \\
\text { jogos". }\end{array}$ \\
\hline Aluno 5: "A tia deveria fazer isso aqui!" & $\begin{array}{l}\text { Aluno 10: "Gostaria } \\
\text { voltassem". }\end{array}$ \\
\hline
\end{tabular}

Mediante a análise do Quadro 3, percebe-se que a oficina criou um ambiente descontraído, desempenhando, desta maneira, uma possível função ascendente perante a aprendizagem dos alunos. Isto porque a experiência vivenciada por eles permitiu aspectos cognitivos que foram mobilizados durante a aplicação do conhecimento adquirido ao longo da oficina. Nota-se ainda, na fala de alguns alunos, um afloramento de concepções sobre o seu papel como sujeito crítico e responsável pelo meio ambiente (Alunos 2, 6 e 8).

Ressalte-se que alguns participantes tiveram certa dificuldade de entender as regras estabelecidas para a execução da atividade, e tentaram modificá-las durante a aplicação da oficina. Tal fato corrobora as ideias de Brougère sobre o sistema de regras em uma situação lúdica, pois o autor pontua que "as regras não preexistem à brincadeira, mas são produzidas à medida que se desenvolve a brincadeira" (BROUGÈRE, 1995, p. 101).

No geral, entende-se que, por se tratar de uma atividade lúdica, é aceitável que a maioria dos alunos tenha achado interessante a proposta, pois o lúdico é encantador e modifica o cenário habitual onde venha a ser inserido, tornando-se atrativo, pois estabelece uma aura de curiosidade sobre os participantes da atividade, o que leva a acreditar que favorece situações ricas para a aquisição de aprendizagens. Sendo assim, o lúdico sempre será bem aceito entre os alunos, independentemente de suas idades e níveis educacionais, visto que a sua inserção pode contribuir com a quebra de paradigmas que estão atrelados ao fracasso escolar. 
Verificou-se, também, que alguns alunos apresentaram dificuldades em compreender os jogos e brinquedos que foram desenvolvidos, mas, a partir do espírito de cooperação entre os mesmos, foi possível observar a evolução intelectual destes, diante das atividades. Tudo leva a crer que, tal como aponta Rego (2000, p. 79), o trabalho com atividades lúdicas é capaz de "estimular o intelecto". Pois, para Piaget (1998), a atividade lúdica representa o berço obrigatório das atividades intelectuais da criança, sendo, por isso, indispensável à prática educativa.

Finalmente, uma fala nos chamou bastante a atenção, a qual se refere ao fragmento textual do discurso do Aluno 5, pois, ao informar que "A tia deveria fazer isso aqui!", este aluno estava inconscientemente cobrando uma "responsabilidade lúdica" por parte do seu professor, tal como defendida por Felício (2011) e já supracitado anteriormente. Portanto, para alcançar o sucesso escolar, é preciso que os educadores criem possibilidades que tangenciem a motivação dos alunos ao raciocínio e a criatividade, fazendo, deste modo, emergir novas habilidades e competências na vida social desses alunos. Neste viés, a oficina com materiais reciclados mostrou que o nosso conhecimento não é o produto apenas de nossa capacidade de reflexão interna, mas, sobretudo, de nossa interação com o meio que nos cerca e da forma como se atribuem significados às coisas (ANDRADE, 2012).

\section{Considerações Finais}

Os resultados obtidos a partir da aplicação da oficina (voltada para a produção de brinquedos e jogos elaborados com o uso de materiais reciclados) para crianças do 30 ano do Ensino Fundamental I revelaram que é amplamente viável inserir o lúdico no cotidiano escolar das crianças, pois esta "intervenção lúdica" proporcionou, de forma diferenciada, dinâmica e atrativa, a criação de meios que promoveram o desenvolvimento de habilidades cognitivas que certamente foram utilizadas na construção do conhecimento sobre temas relacionados à Ciência e ao meio ambiente, além de favorecer aspectos que contribuíssem para uma formação crítica, relacionada com os aspectos ambientais.

Como ferramentas pedagógicas, os brinquedos e jogos podem ser excelentes basilares para a promoção de uma aprendizagem mais eficaz para os alunos. Porém, é importante que estes sejam previamente planejados e alinhados aos objetivos cognitivos que se deseje alcançar nos alunos. Conforme visto, a produção coletiva de jogos e brinquedos, a partir de materiais reutilizáveis, consistiu em uma proposta econômica, divertida e, sobretudo, ecologicamente correta, despertando a criatividade e contribuindo para conscientizar as crianças sobre os cuidados necessários com o meio ambiente.

De tal modo, a produção e utilização de ferramentas pedagógicas obtidas por meio de materiais recicláveis, dentro do contexto escolar, estimularam a curiosidade dos alunos sobre os conteúdos didáticos que foram inseridos na construção da proposta lúdica executada, além de

DOI: Em andamento. 
contribuir e fortalecer aspectos colaboracionistas dentro da sala de aula._Tudo indica que as atividades lúdicas planejadas e aplicadas no ambiente escolar tendem a promover a mobilização de saberes dos alunos, instigam o seu senso crítico e intensificam aspectos que promovem um aprendizado de forma colaborativa, permitindo, assim, que habilidades e competências possam ser desencadeadas coletivamente. Todavia, sabe-se que as habilidades cognitivas são estabelecidas individualmente, mas não há impeditivo ao fato de se adquirir experiências com o outro; com isso, acredita-se que a troca de experiências que são vivenciadas entre os indivíduos cause, individualmente, a possibilidade de se reformular e reestruturar o nosso próprio conhecimento.

Diante das considerações realizadas e dos resultados apresentados, pode-se inferir que as crianças responderam positivamente a todos os estímulos oferecidos pelo lúdico, tais como curiosidade, receptividade à atividade, estreitamento das relações aluno-aluno e alunoprofessores, motivação, capacidade de resolver os problemas de modo mais dinâmico e sagaz, etc.

\section{Referências}

ANDRADE, C. C. A fenomenologia da percepção a partir da autopoiesis de Humberto Maturana e Francisco Varela. Griot - Revista de Filosofia, v. 6, n. 2, 2012.

ANTUNES, A. L. O esplendor de Portugal. Rio de Janeiro: Rocco, 1999.

BICUDO, M. A. V. Fenomenologia: Confrontos e Avanços. São Paulo: Cortez, 2000.

BOMTEMPO, E. Como e para que montar uma Brinquedoteca. Anais - 1‥ Congresso Brasileiro de Ludodiagnóstico, São Paulo, Faculdades Metropolitanas Unidas - FMU, p. 69-70, 2009.

BRÃO, A. F. S.; PEREIRA, A. M. T. B. Biotecnétika: Possibilidades do jogo no ensino de genética. Revista Electrónica de Enseñanza de las Ciencias, v. 14, n. 1, p. 55-76, 2015.

BRASIL. Ministério da Educação. Secretaria de Educação Média e Tecnológica. Parâmetros curriculares nacionais. Brasília: MEC; SEMTEC, 1997.

BROUGÈRE, G. Brinquedo e cultura. São Paulo: Cortez, 1995.

BRUNER, J. S; RATNER, N. Games, Social Exchange and the Acquisition of Langage. Journal of child Language. V.5, n. 3, p. 391-491-401, 1978.

CACHAPUZ, A. et al. A Necessária Renovação do Ensino das Ciências. 3ạ ed. São Paulo: Cortez, 2011.

CARVALHO, I. C. M. Educação Ambiental: a formação do sujeito ecológico. São Paulo: Cortês, 2008.

100 DOI: Em andamento.

R. Bras. de Ensino de C\&T 
CASTOLDI, R.; POLINARSKI, C. A. Considerações sobre estágio supervisionado por alunos licenciandos em Ciências Biológicas. In: VII Encontro Nacional de Pesquisa em Educação em Ciências, Florianópolis, 2009. Anais do VII ENPEC, Belo Horizonte: ABRAPEC, 2009.

CAVALCANTI, E. L. D. O Lúdico e a Avaliação da Aprendizagem: Possibilidades para o ensino e aprendizagem de química - Tese de Doutorado. UFG/UFU/UFMS, 2011.

COLLINS, A. et al. Dangeous \& Dragon, Livro do Mestre, Abril: São Paulo, 2005.

CUNHA, M. B. Jogos no Ensino de Química: Considerações Teóricas para sua Utilização em Sala de Aula. Química Nova na Escola, v. 34, n. 2, p. 92-98, 2012.

DELIZOICOV, D.; ZANETIC, J. A proposta de interdisciplinaridade e o seu impacto no ensino municipal de 10 grau. In PONTUSCHKA, N. Ousadia no diálogo - interdisciplinaridade na escola pública. São Paulo. Loyola, 1993.

FELÍCIO, C. M. Do Compromisso a Responsabilidade Lúdica: Ludismo em Ensino de Química na Formação Básica. Tese de doutorado - Universidade Federal de Goiás, 2011.

FERNANDES, R. S. et al. Uso da percepção ambiental como instrumento de gestão em aplicações ligadas às áreas educacional, social e ambiental. Vitória, 2003. Disponível em:< http://www.redeceas.esalq.usp.br/noticias/Percepcao_Ambiental.pdf/>. Acesso em: $10 \mathrm{dez}$. 2014.

FIALHO, N. N. Jogos no ensino de química e biologia. Curitiba, IBTEX, 2007.

FREIRE, P. N. A. Que fazer: teoria e prática em educação popular. Petrópolis, 1993.

GOUVÊA, L. G.; SUART, R. C. Análise das Interações Dialógicas e Habilidades Cognitivas desenvolvidas durante a aplicação de um jogo didático no ensino de química. Ciências \& Cognição, v. 19, n. 1, p. 27-46, 2014.

HAINEY, T. et al. Students' attitudes toward playing games and using games in education: Comparing Scotland and the Netherlands. Computers and Education, v. 69, p. 474-484, 2013.

HUIZINGA, J. Homo ludens: o jogo como elemento da cultura. 2 ed. São Paulo: perspectiva, 1980. KISHIMOTO, M. T. O jogo e a Educação Infantil. Pioneira Thomson Learning. São Paulo, 2003. p. 13.

T. M. Jogos Infantis: O jogo, a criança e a educação. 6 ed. Petrópolis: Vozes, 1999.

KOLB, Y.; KOLB, D. A. Learning to play, playing to learn - A Case study of a ludic learning space. Journal of Organizational Chance Monagement. Vol. 23, № 1, p. 26-50, 2010.

MARTINS, J.; BICUDO, M. A. V. A Pesquisa qualitativa em psicologia: fundamentos e recursos básicos. São Paulo: EDUC/Moraes, 1989.

MOYLES, J. R. Só brincar? O papel do brincar na Educação Infantil. Porto Alegre: Artmed, 2002.

R. B. E. C. T., vol 8, núm. 3, mai-ago.2015 ISSN - 1982-873X

DOI: Em andamento. 
NÓBREGA, M. L. S. et al. Educação e Convivência com o Semiárido. Juazeiro: Selo Editorial RESAB, 2011.

NOGUERA, J. O. C. (professor Conteudista- UFSM). Curso de Especialização em Educação Ambiental. Disciplina Abordagem das Questões Ambientais: Poluição Urbana, Ar e Resíduos Sólidos e Urbanos. Polo de Apoio Presencial - Panambi - RS, 2010.

PACKER, M. Cultural work on the kindergarten playground: Articulating the ground of play. Human Development, 37, p. 259-276, 1994.

PIAGET, Jean. A Psicologia da criança. Rio de Janeiro: Bertrand Brasil, 1998.

POUPART, J. et al. A Pesquisa Qualitativa - Enfoques epistemológicos e metodológicos. 3. Ed. Petrópolis, RJ: Vozes, 2012.

REGO, T. C. Vygotsky: uma perspectiva histórico-cultural da educação. 10. ed. Petrópolis: Vozes, 2000.

REIGOTA, M. O que é educação ambiental. São Paulo, Brasiliense, 2001.

RIZZI, L. et al. Atividades Lúdicas na Educação da Criança: Subsídios Práticos para o Trabalho na Pré-escola e nas Séries Iniciais do 1으 Grau. 2ª ed.: Ática, 1987.

ROJAS, J. et al. Fenomenologia e rigor na pesquisa educacional: a experiência da UFMS. Anais do IV SIPQ, 2012 p. 1-10.

RONCA, P. A. C. A aula operatória e a construção do conhecimento. São Paulo: Edisplan, 1989.

SIAULYS, M. O. C. Brincar para todos. Brasília: MEC/SEESP, 2005.

SILVA, A. S.; HJORTH, L. Playful Urban Spaces: A Historical Approach to Mobile Games. Simulation \& Gaming, 40: 602, 2009.

SOARES, M. H. F. B. Jogos e atividades lúdicas para o Ensino de Química. Goiânia, GO: Kelps, 2013.

SOUTO-MANNING, M. Playing with power and privilege: Theatre games in teacher education. Teaching and Teacher Education, v. 27, n. 6, p. 997-1007, 2011.

SOUZA, L. H. P.; GOUVÊA, G. Oficinas pedagógicas de ciências: os movimentos pedagógicos predominantes na formação continuada de professores. Ciência e educação, v. 12, n. 3, p. 303313, 2006.

SULAIMAN, S. N. Educação ambiental, sustentabilidade e ciência: o papel da mídia na difusão de conhecimentos científicos. Ciência \& Educação, v. 17, n. 3, p. 645-662, 2011

TRISTÃO, F. C. D. Ser professora de bebês: um estudo de caso de uma creche conveniada. Florianópolis, 2004. 206 f. Dissertação (Mestrado em Educação) -, Centro de Ciências da Educação. Universidade Federal de Santa Catarina, Florianópolis, 2004.

102 DOI: Em andamento.

R. Bras. de Ensino de C\&T 
VIEIRA, E., VALQUIND, L. “Oficinas de Ensino: O quê? Por quê? Como?”. 4ํ ed. EDIPUCRS. Porto Alegre - RS. 2002.

VYGOTSKY, L. S. A formação social da mente. In: Interação entre aprendizado e desenvolvimento. 70 ed. - São Paulo: Martins Fontes, p. 87 - 106, 2007.

L. S. A formação social da mente: o desenvolvimento dos processos psicológicos superiores. São Paulo, SP: Martins Fontes, 1989.

Ana Carolina Rosa da Silva - Graduada em Licenciatura em Ciências da Natureza pela Universidade Federal do Vale do São Francisco - UNIVASF (Campus São Raimundo Nonato - PI). E-mail: carolina.rsilva20@gmail.com

Ludmylla Ribeiro dos Santos - Graduada em Licenciatura em Ciências da Natureza pela Universidade Federal do Vale do São Francisco - UNIVASF (Campus São Raimundo Nonato - PI). Email: ludmyllabenevides@gmail.com

Paloma Lopes de Lacerda - Graduada em Licenciatura em Ciências da Natureza pela Universidade Federal do Vale do São Francisco - UNIVASF (Campus São Raimundo Nonato - PI). E-mail: palomalopes36@gmail.com

Fabiana Mota da Silva - Graduanda em Licenciatura em Ciências da Natureza pela Universidade Federal do Vale do São Francisco - UNIVASF (Campus São Raimundo Nonato - PI). E-mail: biliuskinha@gmail.com

Elieide Livia Ribeiro da Costa - Graduanda em Licenciatura em Ciências da Natureza pela Universidade Federal do Vale do São Francisco - UNIVASF (Campus São Raimundo Nonato - PI). Email: elieidelivia21@hotmail.com

Maria das Graças Cleophas. Doutoranda em Ensino de Ciências (Ênfase em Química) pela Universidade Federal Rural de Pernambuco - UFRPE. Professora do Instituto Latino-Americano da Ciências da Vida e da Natureza (ILACVN) da Universidade Federal da Integração Latino-Americana (UNILA). E-mail: maria.porto@unila.edu.br

DOI: Em andamento. 